\title{
Short communication: Adipocyte sizes in the digital fat pad and their relationship to body condition in dairy cows
}

\author{
S. Hiss-Pesch, ${ }^{*}$ J. Weise, B. Heitkönig, and H. Sauerwein \\ Institute of Animal Science, Physiology and Hygiene Unit, University of Bonn, 53113 Bonn, Germany
}

\section{ABSTRACT}

Lameness and body condition are closely related. Recent studies have shown that cows with low body condition score (BCS) have a greater risk for developing lameness than cows with higher BCS. Among other reasons, this relationship might be related to the reduced thickness of the digital fat cushion in lean cows. The digital cushion is not a homogeneous structure but consists of different fat pads and connective tissue. We hypothesized that either high or low BCS will result in concordant adipocyte sizes in the fat pads of the digital cushion and subcutaneous tailhead fat irrespective of the localization of the latter. Right front claws were collected from 18 Holstein Friesian cows. Cows were selected according to their BCS: 9 cows with BCS $<3$ (low BCS) and 9 cows with BCS $\geq 3$ (high BCS). After dissecting the horn capsule of the lateral claw, samples of the axial and abaxial fat pads were prepared for histomorphological examinations (adipocyte size measurement) and protein abundance of vascular endothelial growth factor A (VEGF-A) via Western blotting. In addition, fat samples were excised from the tailhead of all cows and used for the same purposes. Adipocyte size in tailhead fat was greater in high-BCS than in low-BCS cows. Similar differences between the BCS groups were apparent for adipocytes from the axial fat pad, although adipocytes in tailhead fat were larger than those in the digital cushion. In contrast to that in the axial fat pad and tailhead fat, adipocyte size in the abaxial fat pad was similar in cows from both BCS groups. A relationship between adipocyte size and VEGF-A protein was only confirmed for the axial fat pad, not for the other fat depots. When comparing BCS groups, differences in VEGF-A protein abundance between high-BCS and low-BCS cows were also limited to the axial fat pad, being absent in tailhead fat and the abaxial fat pad. Taken together, our results show that the fat pads from the digital cushion should not be

Received August 10, 2018.

Accepted January 28, 2019.

*Corresponding author: s.hiss@uni-bonn.de considered uniform adipose tissue locations but rather discrete units reacting differently to fat mobilization.

Key words: claw fat pad, body condition score, adipocyte size, vascular endothelial growth factor A (VEGF-A)

\section{Short Communication}

Lameness and body condition are closely related in dairy cows. Recent studies have shown that cows with low BCS have a greater risk for developing lameness than cows with higher BCS (Hoedemaker et al., 2009; Randall et al., 2015). Bicalho and coworkers identified a positive association of BCS and the thickness of the digital cushion and proposed that low BCS is a risk factor for lameness, not only a consequence (Bicalho et al., 2009). The digital cushion, a complex shockabsorbing structure located underneath the distal phalanx, consists of 3 parallel fat pads (axial, middle, and abaxial) and connective tissue (Räber et al., 2004). The appearance and lipid content of the digital cushion are influenced by various factors, including parity and location underneath the distal phalanx (Räber et al., 2004, 2006). The lowest lipid content was found in the middle fat pad and the distal abaxial fat pad (Räber et al., 2006; Baird et al., 2010). Ultrasonographic methods have been used as an in vivo tool for measuring the digital cushion thickness (DCT; Bicalho et al., 2009; Machado et al., 2010; Newsome et al., 2017). In these studies, a relationship between BCS and DCT was found. However, the association was much closer in Bicalho et al. (2009) and Machado et al. (2010) than in Newsome et al. (2017), which was explained by different scanning sites (axial vs. medial; Newsome et al., 2017). Therefore, scanning site seems to play a crucial role in analyzing the relationship between BCS and DCT. This directed us to the hypothesis that the fat pads may play different roles within the bovine claw. To address the question whether axial and abaxial fat pads contribute to fat mobilization, we analyzed claw fat from cows with either high or low BCS and measured adipocyte areas from different locations. In addition to adipocyte size, we assessed the protein abundance of 
vascular endothelial growth factor A (VEGF-A) via Western blotting. In adipose tissue, VEGF-A accounts for most of the proangiogenic activity (Hausman and Richardson, 2004) and stimulates adipogenesis (Yamada et al., 2010). In turn, adipogenesis might be used as a dynamic factor for adipocyte growth.

Eighteen Holstein Friesian cows with healthy claws were selected, based on BCS according to the scoring system of Edmonson et al. (1989), in a local abattoir in North Rhine-Westphalia, Germany. Nine cows with BCS $<3$ (low BCS; mean $1.94 \pm 0.41$; parity $3.1 \pm$ 0.77 ) and 9 cows with BCS $\geq 3$ (high BCS; mean $3.58 \pm$ 0.41 ; parity $2.4 \pm 0.63)$ were chosen. The cows were in their first to seventh lactation (mean $2.74 \pm 2.02$ ). The right front claws were dissected in the carpal joint and stored on ice until further preparation. Subcutaneous (sc) fat samples $\left(1 \mathrm{~cm}^{3}\right)$ were excised from the tailhead of all cows and fixed immediately in $4 \%$ paraformaldehyde (Roth, Karlsruhe, Germany) for histomorphology. A second sample for Western blotting was rinsed in $0.9 \% \mathrm{NaCl}$, snap frozen in liquid nitrogen, and stored at $-80^{\circ} \mathrm{C}$ until further use. After transporting the claws to the laboratory, the horn capsule of the lateral claw was removed and samples $\left(1 \mathrm{~cm}^{3}\right)$ of the axial and abaxial fat pads were prepared according to Räber et al. (2004) at the palmar edge of the distal phalanx. The middle fat pad was not sampled because of the multiple strands of connective tissue that affected measurement of adipocyte area. The fat pad samples were fixed in $4 \%$ paraformaldehyde and, as described for the tailhead fat, a second sample was prepared for Western blotting.

After fixation for $72 \mathrm{~h}$, the fat samples for histomorphology were dehydrated and embedded in paraffin wax. Sections were cut $(11 \mu \mathrm{m})$ with a rotation microtome (SLEE, Mainz, Germany), deparaffinized in Roti-Histol (Roth), and rehydrated in a descending isopropanol series. The sections were stained with Mayer's hematoxylin (Merck, Darmstadt, Germany) and 1\% (wt/vol) eosin Y (AppliChem, Darmstadt, Germany) and mounted with Roti-Histokit (Roth). All stained tissue sections were evaluated by light microscopy (Leica DMR, Leica Microsystems, Wetzlar, Germany) connected to a digital color camera (JVC KY-F75U, Hachioji Plant of Victor Company, Tokyo, Japan) according to Akter et al. (2011). Adipocyte areas from 100 adipocytes per section were measured using Diskus software (version 4, Hilgers, Königswinter, Germany).

Tissue homogenates $(500 \mathrm{mg} / \mathrm{mL})$ for WB were prepared with $10 \mathrm{~m} M$ HEPES, $\mathrm{pH} 7.4$, according to Weber et al. (2016). Samples were diluted to $0.5 \mathrm{mg}$ of total protein $/ \mathrm{mL}$ with water and mixed with loading buffer (final concentrations: $0.1 \mathrm{M}$ Tris $\mathrm{HCl} \mathrm{pH} \mathrm{6.8,} 1 \%$ SDS, $0.0032 \%$ bromophenol blue, $10 \%$ glycerol). Five micrograms of soluble protein per lane was used for $8 \%$
SDS-PAGE in duplicate. Separated proteins were transferred onto polyvinylidine difluoride membranes (GE Healthcare Europe, Freiburg, Germany). Membranes were blocked in Tris-buffered saline (TBS) containing 0.1\% Tween 20 (AppliChem) and 10\% RotiBlock (Roth) for $1 \mathrm{~h}$ at room temperature. After blocking, membranes were incubated with mouse-anti-VEGFA antibodies (1:2,500, LS-C2929; LifeSpan BioSciences, Seattle, WA) in TBS containing $0.1 \%$ Tween 20 and $10 \%$ RotiBlock overnight at $4^{\circ} \mathrm{C}$. After washing in TBS, membranes were incubated with a horseradish peroxidase-conjugated secondary antibody (goat-anti-mouse 1:20,000, 1031-05; SouthernBiotech, Birmingham, AL) in TBS containing $0.1 \%$ Tween 20 and $10 \%$ RotiBlock for $1 \mathrm{~h}$ at room temperature. Immunodetection was carried out using an enhanced chemiluminescence detection system (GE Healthcare). Imaging was performed with a VersaDoc MP4000 imaging system (Bio-Rad Laboratories, Munich, Germany), and the band intensities were densitometrically analyzed via the Image Lab software (Bio-Rad). After immunodetection, Indian ink staining was included as a loading and transfer control (Supplemental Figure S1; https://doi.org/10.3168/jds .2018-15531).

Adipocyte size and band intensities obtained for the VEGF-A protein within one fat depot in high-BCS and low-BCS cows were compared by Mann-Whitney U-test. The Wilcoxon signed-rank test was performed to compare adipocyte size and VEGF-A protein content in the 3 fat depots within each cow, including $\alpha$-correction for multiple comparisons. Correlations are given as Spearman rank correlation coefficients. Results are given as mean \pm standard errors of the mean, and differences were considered significant at $P<0.05$.

The adipocyte size in sc tailhead fat was greater in high-BCS than in low-BCS cows (Table 1; $P=0.009$ ), in accordance with De Koster et al. (2016). Similar differences between the BCS groups were apparent for adipocytes from the axial fat pad (Table $1 ; P=0.003$ ), although adipocytes in tailhead fat were larger than those in the digital cushion $(P=0.008$; see also Figure $1)$. In contrast to that in axial and tailhead fat, adipocyte size in the abaxial fat pad was similar in cows from both BCS groups (Table 1; $P>0.05$ ). Correlations between BCS and adipocyte size were confirmed for tailhead fat $(\mathrm{r}=0.6, P<0.006)$ and axial fat pad $(\mathrm{r}=0.6, P=0.004)$. In addition, adipocyte sizes in tailhead and axial fat pad were positively correlated $(\mathrm{r}=0.5, P=0.04)$. The adipocyte size in the abaxial fat pad was not correlated with BCS or with tailhead or axial fat pad. The smaller adipocytes in the axial fat cushion of low-BCS cows support the view that these adipocytes participate in changes of fat mass, as is known for tailhead fat and other fat depots (Akter 

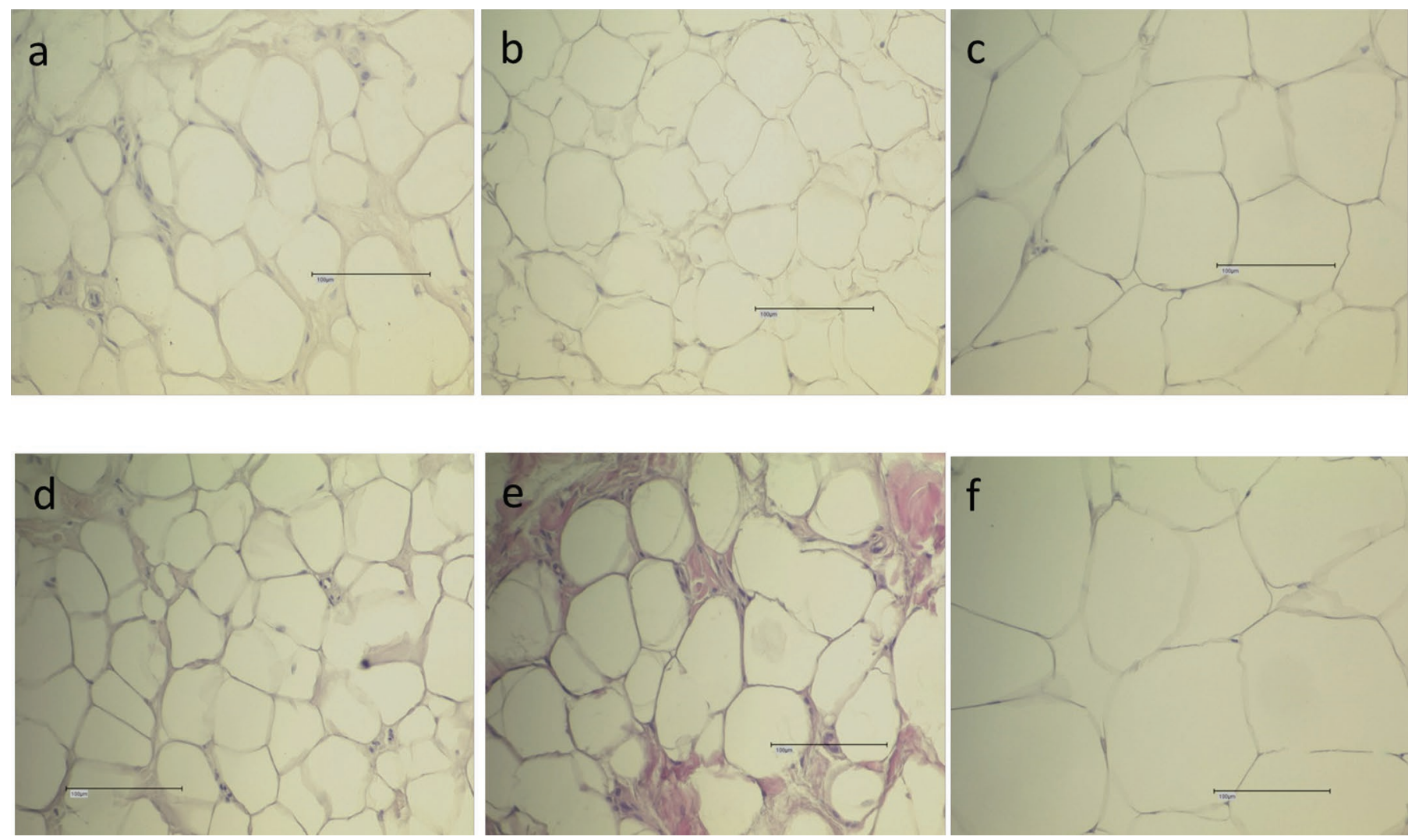

Figure 1. Histological sections (hematoxylin-eosin staining) of the claw fat pad and tailhead fat from one low BCS cow (a-c) and one high BCS cow (d-f); a, d: abaxial claw fat pad; b, e: axial claw fat pad; c, f: tailhead fat. Scale bar $=100 \mu \mathrm{m}$.

et al., 2011; Kenéz et al., 2015). Based on differences between the axial and abaxial fat pads, we can speculate that these fat localizations have different functions, irrespective of their anatomical vicinity. To elucidate this hypothesis, we analyzed the abundance of vascular growth factor VEGF-A in tissue homogenates of the claw fat pads. Synthesis of VEGF-A during cell differentiation has been shown in bovine intramuscular preadipocytes (Yonekura et al., 2013). In mature adipocytes, VEGF-A mRNA expression varies in different fat depots (Yamada et al., 2010), which is explained by different adipocyte sizes. The correlation between VEGF-A mRNA and adipocyte size was 0.47 (Yamada et al., 2010). In our experiment, a relationship between

Table 1. Adipocyte sizes $\left(\mu \mathrm{m}^{2}\right.$, mean $\left.\pm \mathrm{SEM}\right)$ in different fat depots in cows with either high $(\mathrm{n}=9)$ or low $(\mathrm{n}=9)$ BCS

\begin{tabular}{lccc}
\hline Fat depot & High BCS & Low BCS & $P$-value \\
\hline Tailhead & $5,692 \pm 697$ & $3,155 \pm 435$ & 0.009 \\
Axial fat pad & $2,317 \pm 194$ & $1,426 \pm 84$ & 0.003 \\
Abaxial fat pad & $1,576 \pm 64$ & $1,530 \pm 165$ & 0.965 \\
$\Delta$ Axial - abaxial & $741 \pm 180$ & $-104 \pm 130$ & 0.002 \\
\hline
\end{tabular}

adipocyte size and VEGF-A protein could only be confirmed for the axial fat pad $(\mathrm{r}=0.6, P<0.01)$, and not for the other fat depots tested. When comparing the 2 groups, differences in VEGF-A protein abundance between high-BCS and low-BCS cows were also limited to the axial fat pad $(P<0.05)$ and were absent in tailhead fat and the abaxial fat pad (Table 2). This means the axial fat pad is the only fat depot showing differences in cell size and cell dynamics under the prevailing circumstances. The cows used in our study spanned a wide range of parity, which should be taken into account when interpreting the results. Because parity is a known factor affecting the lipid content of the digital cushion (Räber et al., 2004, 2006), there might be an

Table 2. Vascular endothelial growth factor A (VEGF-A) protein (AU, arbitrary units; mean \pm SEM) in different fat depots in cows with either high $(\mathrm{n}=9)$ or low $(\mathrm{n}=9)$ BCS

\begin{tabular}{lccc}
\hline Fat depot & High BCS & Low BCS & $P$-value \\
\hline Tailhead & $0.65 \pm 0.10$ & $0.77 \pm 0.13$ & 0.69 \\
Axial fat pad & $1.22 \pm 0.19$ & $0.67 \pm 0.10$ & 0.05 \\
Abaxial fat pad & $1.29 \pm 0.17$ & $1.13 \pm 0.11$ & 0.56 \\
\hline
\end{tabular}


interaction between our results and parity. The number of animals was not sufficient to include parity in the statistical analysis.

Taken together, our results showed that the axial and abaxial fat pads from the digital cushion should not be considered uniform adipose tissue locations but rather as discrete units reacting differently to fat mobilization. The mechanical exposure for the fat pads analyzed herein is very different. The abaxial fat pad lies underneath the distal phalanx, whereas the axial fat pad is located next to the distal phalanx (Räber et al., 2006). In our study, only axial adipocytes were positively correlated with VEGF-A, reflecting cell growth in the claw fat pad. It remains unclear why we did not observe such a relationship for tailhead adipocytes and VEGF-A. Fat cell growth during excessive nutrient supply may occur at different time points in subcutaneous fat depots.

Concerning in vivo measurement of the DCT, the scanning site seems to be of crucial importance and, as supported by our study, differences in fat mobilization in the different claw fat pads must be considered for appropriate interpretation.

\section{ACKNOWLEDGMENTS}

We thank Iris Gockel-Böhner (Institute of Animal Science, University of Bonn, Bonn, Germany) for excellent technical assistance.

\section{REFERENCES}

Akter, S. H., S. Häussler, S. Dänicke, U. Müller, D. von Soosten, J Rehage, and H. Sauerwein. 2011. Physiological and conjugated linoleic acid-induced changes of adipocyte size in different fat depots of dairy cows during early lactation. J. Dairy Sci. 94:2871-2882.

Baird, L. G., L. E. R. Dawson, I. S. Young, and N. E. O'Connell. 2010. Lipid content and fatty acid composition of the digital cushion of bulls offered different amounts of linseed. J. Anim. Sci. 88:2403-2409.

Bicalho, R. C., V. S. Machado, and L. S. Caixeta. 2009. Lameness in cattle: A debilitating disease or a disease of debilitated cattle? A cross-sectional study of lameness prevalence and thickness of the digital cushion. J. Dairy Sci. 92:3175-3184.

De Koster, J., W. Van den Broeck, L. Hulpio, E. Claeys, M. Van Eetvelde, K. Hermans, M. Hostens, V. Fievez, and G. Opsomer. 2016. Influence of adipocyte size and adipose depot on the in vitro lipolytic activity and insulin sensitivity of adipose tissue in dairy cows at the end of the dry period. J. Dairy Sci. 99:2319-2328.

Edmonson, A. J., I. J. Lean, L. D. Weaver, T. Farver, and G. Webster. 1989. A Body Condition Scoring chart for Holstein dairy cows. J. Dairy Sci. 72:68-78.

Hausman, G. J., and R. L. Richardson. 2004. Adipose tissue angiogenesis. J. Anim. Sci. 82:925-934.

Hoedemaker, M., D. Prange, and Y. Gundelach. 2009. Body condition change ante- and postpartum, health and reproductive performance in German Holstein cows. Reprod. Domest. Anim. 44:167173.

Kenéz, A., A. Kulcsar, F. Kluge, I. Benbelkacem, K. Hansen, L. Locher, U. Meyer, J. Rehage, S. Dänicke, and C. Huber. 2015. Changes of adipose tissue morphology and composition during late pregnancy and early lactation in dairy cows. PLoS One 10:e0127208.

Machado, V. S., L. S. Caixeta, J. A. A. McArt, and R. C. Bicalho. 2010. The effect of claw horn disruption lesions and body condition score at dry-off on survivability, reproductive performance, and milk production in the subsequent lactation. J. Dairy Sci. 93:4071-4078.

Newsome, R. F., M. J. Green, N. J. Bell, N. J. Bollard, C. S. Mason, H. R. Whay, and J. N. Huxley. 2017. A prospective cohort study of digital cushion and corium thickness. Part 1: Associations with body condition, lesion incidence, and proximity to calving. J. Dairy Sci. 100:4745-4758

Räber, M., Ch. J. Lischer, H. Geyer, and P. Ossent. 2004. The bovine digital cushion-A descriptive anatomical study. Vet. J. 167:258 264.

Räber, M., M. R. L. Scheeder, P. Ossent, Ch. J. Lischer, and H. Geyer. 2006. The content and composition of lipids in the digital cushion of the bovine claw with respect to age and location-A preliminary report. Vet. J. 172:173-177.

Randall, L. V., M. J. Green, M. G. G. Chagunda, C. Mason, S. C. Archer, L. E. Green, and J. N. Huxley. 2015. Low body condition predisposes cattle to lameness: An 8-year study of one dairy herd. J. Dairy Sci. 98:3766-3777.

Weber, M., L. Locher, K. Huber, J. Rehage, R. Tienken, U. Meyer, S. Dänicke, L. Webb, H. Sauerwein, and M. Mielenz. 2016. Longitudinal changes in adipose tissue of dairy cows from late pregnancy to lactation. Part 2: The SIRT-PPARGC1A axis and its relationship with the adiponectin system. J. Dairy Sci. 99:1560-1570.

Yamada, T., S. Kawakami, and N. Nakanishi. 2010. Fat depot-specific differences in angiogenic growth factor gene expression and its relation to adipocyte size in cattle. J. Vet. Med. Sci. 72:991-997.

Yonekura, S., Y. Tokutake, S. Hirota, M. T. Rose, K. Katoh, and H. Aso. 2013. Proliferating bovine intramuscular preadipocyte cells synthesize leptin. Domest. Anim. Endocrinol. 45:33-37. 